\title{
High Selectivity of Alkanes Production by Calcium Basic Soap Thermal Decarboxylation
}

\author{
Godlief F.Neonufa ${ }^{1,2,{ }^{*}}$, Meiti Pratiwi ${ }^{1}$, Tatang H. Soerawidjaja ${ }^{1}$ and Tirto Prakoso ${ }^{1}$ \\ ${ }^{1}$ ITB, Department of Chemical Engineering, 40132 Bandung, Indonesia \\ ${ }^{2}$ UKAW, Department of Agriculture Product Technology, 85000 Kupang, Indonesia
}

\begin{abstract}
Renewable fuel production from vegetable oil and fat or its fatty acids by direct decarboxylation has been widely reported. An innovative approach to produce drop-in fuel via thermal catalytic decarboxylation of basic soap derived from palm stearin reported in this research. The catalytic effect of the calcium and magnesium metals in the basic soap and its decarboxylation on drop-in fuel yield and product distribution was studied. The catalytic effect was tested in the temperature range up to $370^{\circ} \mathrm{C}$ and atmospheric pressure for 5 hours in a batch reactor. It has been proved that the calcium basic soap decarboxylation, effectively produce the drop-in fuel in carbon ranges $\mathrm{C}_{8}-\mathrm{C}_{20}$, in which more than $78 \%$ selectivity toward alkane. Whereas, only $70 \%$ selectivity toward alkane has been resulted from the magnesium basic soap decarboxylation.
\end{abstract}

\section{Introduction}

Nowadays, a considerable of attention has been devoted to producing renewable diesel (drop-in fuel) via deoxygenation of vegetable oils and fats or fatty acids. Biodiesel as one of the renewable liquid fuels that have been popular can only be used in a certain amount by blended with petrodiesel as an additive. For instance, a blended fuel comprised of $20 \%$ biodiesel and $80 \%$ petrodiesel is called B20 [1]. The direct production of liquid biohydrocarbons from vegetable oils and fats via the hydrodeoxigenation method has been reported by many researchers. The disadvantages of the hydrodeoxigenation process of oils and fats are using noble metal catalysts [2] and require fossil fuel-derived hydrogen. So that the process is not $100 \%$ renewable.

One promising deoxygenation method for the production of drop-in fuels is basic soap decarboxylation. This method does not require $\mathrm{H}_{2}$ (when the soap derived from saturated fatty acids) or slightly $\mathrm{H}_{2}$ (when the soap derived from unsaturated fatty acids), can be operated at atmospheric pressure and only the alkaline earth and transition metals are used to prepare of the basic soap and as a catalyst for decarboxylation of it soap [3].

Decarboxylation of basic soaps (e.g., magnesium soap) into drop-in fuels, illustrated by the equation of reaction 1 .

$$
(\mathrm{R}-\mathrm{COO}) \mathrm{M}_{\mathrm{g}}(\mathrm{OH}) \rightarrow \mathrm{RH}+\mathrm{M}_{\mathrm{g}} \mathrm{CO}_{3}
$$

The factors that determine the success rate of basic soap decarboxylation into liquid biohydrocarbons (dropin fuels) lies in the level of perfection of basic soap prepared and its hydroxide resistance during decarboxylation [4]. Therefore, the selection of metals for the prepare of basic soaps, highly determined the success rate of the basic soap production and its decarboxylation. Hydroxide and oxide magnesium compound have been reported can be good catalyst for the process of decarboxylation of oils and fats [5-8]. A series of decarboxylation experiments to synthesize drop-in fuels from magnesium basic soaps derived from palm stearin has been studied in our previous study. The drop-in fuel that has been resulted consist of a mixture of biohydrocarbons, which include n-alkane, iso-alkane and 1-alkene fractions, in $\mathrm{C}_{8}-\mathrm{C}_{20}$ carbon number. In addition, it also detected a small amount of ketone products.

The presence of the 1-alkene and the ketone component in the fuel product, related to the character of the magnesium basic soaps decomposition. It is decompose more rapidly and at low temperature, i.e., begins at about $300^{\circ} \mathrm{C}$, and becomes very rapid between $350^{\circ}$ and $400^{\circ} \mathrm{C}$ [4]. Therefore, the hydroxide of [(R$\mathrm{COO}) \mathrm{Mg}(\mathrm{OH})]$ is possible to discharge as water, leaved behind a neutral magnesium soap $[(\mathrm{R}-\mathrm{COO}) \mathrm{Mg}(\mathrm{R}-$ $\mathrm{COO})]$, and then the soap lose its basicity before the maximum temperature for decarboxylation is achieved. When the neutral soap decarboxylated, that's result the ketone, and then the decomposition of the ketone would result 1 -alkene, as illustrated by the equation of reaction 2.

$$
(\mathrm{R}-\mathrm{COO})_{2} \mathrm{Mg} \rightarrow \mathrm{R}-\mathrm{CO}-\mathrm{R}+\mathrm{MgCO}_{3}
$$

Both 1-alkene or ketone, are not expected in all dropin fuel, because it causes the fuel instability [9]. In addition, the 1-alkenes can reduce cetane number of the green-diesel [10] and become the precursors for oxidation reactions. In principle, the long chain biohydrocarbon fractions, especially n-alkanes, are much

Corresponding author: godlief17@students.itb.ac.id 
more important in green diesel fuel to increase the cetane number than 1-alkene [11]. Therefore, the metal for preparing of the basic soap, must be carefully selected, which have high catalytic and selectivity ability to form n-alkanes during the basic soap decarboxylation.

Sato [12] demonstrated experimentally that calcite, $\mathrm{CaCO}_{3}$, can promote the degradation of fatty acids into n-alkanes. Catalysts with core of calcium metal was reported has the catalytic effects to convert fatty acids into n-alkanes, particularlly in gasoline boiling range $[3,13]$, via the pyrolysis reaction of calcium soap.

Calcium soaps have been reported [4], decompose begin at $350^{\circ}$ to $400^{\circ} \mathrm{C}$, and becomes rapid at $450^{\circ}$ $500^{\circ} \mathrm{C}$. Therefore, hydroxide molecule of the calcium basic soaps may still remain in the soap until their decarboxylation temperature reaches $370^{\circ} \mathrm{C}$, and resulting a lot of n-alkanes of long chain during decarboxylation of the basic soap. The purpose of this study is to prove that the decarboxylation of reactants from calcium basic soaps derived from palm stearin, can produce high green diesel content of $n$-alkanes and free ketones.

\section{Experimental}

Magnesium acetate tetrahydrate $\left[\mathrm{Mg}\left(\mathrm{OOC}_{2} \mathrm{H}_{5}\right)_{2} \cdot 4 \mathrm{H}_{2} \mathrm{O}\right]$ and iron acetate dihydrate $\left[\mathrm{Fe}\left(\mathrm{OOC}_{2} \mathrm{H}_{5}\right)_{3} \cdot 2 \mathrm{H}_{2} \mathrm{O}\right]$ was supplied by Merck (analytical grade), were used to make the soap. The palm stearin oil obtained from PT. Ecogreen, Batam. The magnesium and calcium basic soap were prepared by metathesis process. The process started by mixing oils and hot ethanol $\left(70^{\circ} \mathrm{C}\right)$. Then, stirred the mixture with an aqueous solution of sodium hydroxide at $20 \%(\mathrm{w} / \mathrm{w})$ until it has reached a firm consistency. Magnesium acetate tetrahydrate and iron acetate dihydrate solution in distilled water added slowly to the mixture while continually stirring. The resulting basic soaps were filtered, washed (by hot water) and dried for using in subsequent experiments. Saponification reactions were performed in a glass batch reactors.

Decarboxylation reaction were performed in a glass reactor $(100 \mathrm{ml})$ operating in a semi batch mode and at atmospheric pressure. Decarboxylation proceeded at temperatures up to $370^{\circ} \mathrm{C}$ for 5 hours. Heat was supplied by a high temperature heating mantle and both liquid (the melted soap) and vapor temperatures were measured with thermocouple. Magnesium and calcium basic soap both from palm stearin oil as a reactant model compound and the reactions were performed without other catalysts.

In a typical semi batch experiment, a number of basic soaps carefully weighed were placed into the reactor. After that, the reactor was flushed with nitrogen in order to remove the remaining oxygen. Then, the reactor was heated to $370^{\circ} \mathrm{C}$ and maintained for 5 hours at that temperature. The liquid products were collected in a beaker.
The liquid reaction products were analyzed by gas chromatograph (GC) Shimadzu 2010 equipped with a capillary column (rtx-1) with dimensions of $30 \mathrm{~m}$ x 0.25 $\mathrm{mm} \times 0.25 \mu \mathrm{m}$ and flame ionization detector (FID). One microliter of sample was injected into the GC-FID with a split ratio 1:50 and the carrier gas (helium) flow rate was $42.9 \mathrm{ml} / \mathrm{min}$. The injector and detector temperature were $340^{\circ} \mathrm{C}$ and $340^{\circ} \mathrm{C}$, respectively. The following chromatographic temperature program was used for analysis: $40^{\circ} \mathrm{C}$ (at first) $-300^{\circ} \mathrm{C}\left(5^{\circ} \mathrm{C} / \mathrm{min}\right)-340^{\circ} \mathrm{C}$ $\left(1^{\circ} \mathrm{C} / \mathrm{min}\right.$, constant $\left.45 \mathrm{~min}\right)$. A number of chemical standards were purchased enabling product identification and calibration.

\section{Results and Discussion}

The thermal catalytic decarboxylation of two different types of basic soaps, i.e., magnesium and calcium basic soap derived from palm stearin oils, respectively was studied. The reaction was performed at $370^{\circ} \mathrm{C}$ and atmospheric pressure for 5 hours.

\subsection{Product yields from decarboxylation}

Table 1 shows various products resulted of $\mathrm{Mg}$ and Calcium basic soap decarboxylation.

Table 1. Material balance for the reaction product.

\begin{tabular}{|l|r|r|}
\hline \multirow{2}{*}{\multicolumn{1}{|c|}{ Material }} & \multicolumn{2}{|c|}{ Yield (wt \% of feed) } \\
\cline { 2 - 3 } & \multicolumn{1}{|c|}{ Mg base } & \multicolumn{1}{c|}{ Ca base } \\
\hline liquid biohydrocarbons & 67.21 & 63.33 \\
\hline water & 1.14 & 1.42 \\
\hline solid residues & 28.23 & 32.93 \\
\hline gas & 3.42 & 2.32 \\
\hline
\end{tabular}

Table 1 shows that the liquid biohydrocarbon resulted of magnesium basic soap is $67.21 \%$-wt, greater than $63.33 \%$-wt of calcium basic soap. The calcium basic soap decarboxylation result the most solid residues product (i.e., 32.93\%-wt) than its counterpart magnesium (28.23\% -wt).

The gas products by calcium basic soap less than magnesium soap. This implies that magnesium basic soap is faster decomposed to light products than calcium. According to GC-TCD chromatogram, the gases generated from both magnesium and calcium basic soaps contain $\mathrm{H}_{2}, \mathrm{CO}_{2}$ and $\mathrm{CH}_{4}$.

\subsection{Qualitative analysis of liquid hydrocarbon}

Figure 1 shows functional group profiles in liquid biohydrocarbon resulting from decarboxylation of both magnesium and calcium basic soaps, using Fourier transform infrared (FTIR) spectroscopy. 


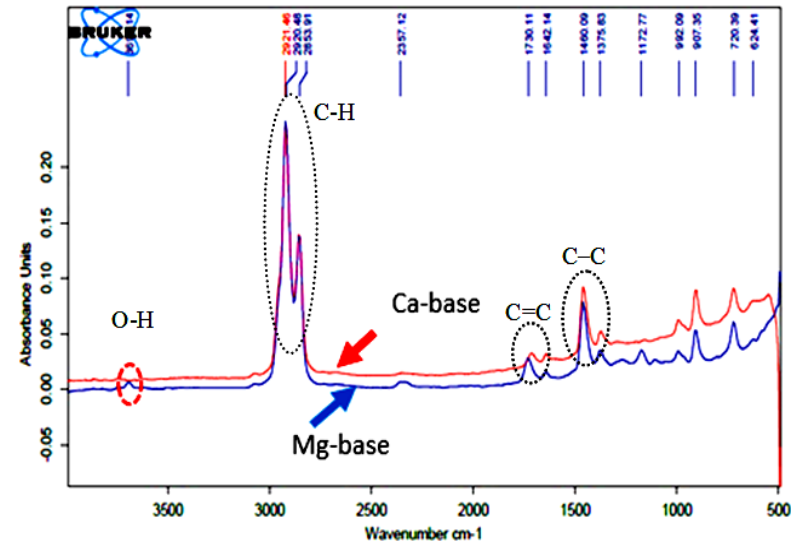

Fig. 1. FTIR of liquid biohydrocarbon from basic soap: red line, $\mathrm{Ca}$ base, and blue line, $\mathrm{Mg}$ base.

Figure 1 shows that the liquid product was resulted from both the magnesium and calcium basic soap decarboxylation contains the $\mathrm{C}-\mathrm{C}, \mathrm{C}=\mathrm{C}$ and $\mathrm{C}-\mathrm{H}$ functional groups in the range 1375-1460, 642-1730, and $2853-2921 \mathrm{~cm}^{-1}$, respectively. Whereas, the hydroxide (O-H) group at the wave number $3618 \mathrm{~cm}^{-1}$, only detected in the liquid product of the basic soap magnesium. The results mentioned above show that oxygenated compounds still exist in the liquid biohydrocarbon from magnesium basic soap than calcium basic soap.

The GC-MS analysis results, also confirmed that about $2.6 \%$ - mole of ketone compounds are present in the liquid biohydrocarbon from magnesium basic soap. Whereas, it is not detected in the liquid biohydocarbon from calcium basic soap.

\subsection{Distribution of liquid products profile}

The GC-FID chromatogram pattern, related to the distribution of the liquid biohydrocarbon fraction resulting from the decarboxylation of both magnesium and calcium basic soaps derived from palm stearin oil, is shown in Fig. 2. Figure 2 shows that the decarboxylation of magnesium and calcium basic soaps produce liquid biohydrocarbons in the range of $\mathrm{C}_{8}-\mathrm{C}_{20}$ carbon number. According to GC-FID chromatogram the n-pentadecane and n-tetradecane was the main product in the decarboxylation of both magnesium and calcium basic soap. However, few of the 1-pentadecene also was formed in the decarboxylation of magnesium basic soap. In case of n-octadecane, significantly were only formed in the decarboxylation of calcium basic soap. It means that calcium can catalyze the polymerization reaction of short-chain into long-chain liquid biohydrocarbon molecules. Figure 2 also shows that the liquid biohydrocarbon product contains alkane (consisting of nalkanes and iso-alkanes) and alkene compounds. In case of long chain alkanes (e.g., $\mathrm{C}_{14}, \mathrm{C}_{15}$ and $\mathrm{C}_{18}$ ) are higher produced in the decarboxylation of calcium basic soap than magnesium basic soap. Whereas, in case of the $\mathrm{C}_{8^{-}}$ $\mathrm{C}_{13}$ product, always produced n-alkane and 1-alkenes compounds in the relatively equal peak height in both basic

soap.

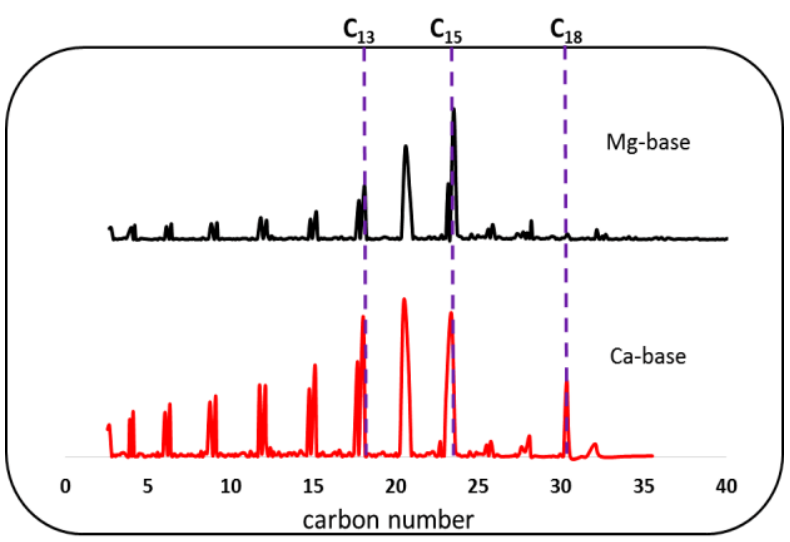

Fig. 2. GC-FID chromatograms patterns for liquid biohydrocarbon fractions.

\subsection{Quantitative analysis: alkane and olefin}

Figure 3 shows the results of the molar fraction analysis of the liquid biohydrocarbons in the range of $\mathrm{C}_{8}$ to $\mathrm{C}_{20}$ carbon number, obtained from the decarboxylation of both magnesium and calcium basic soaps.

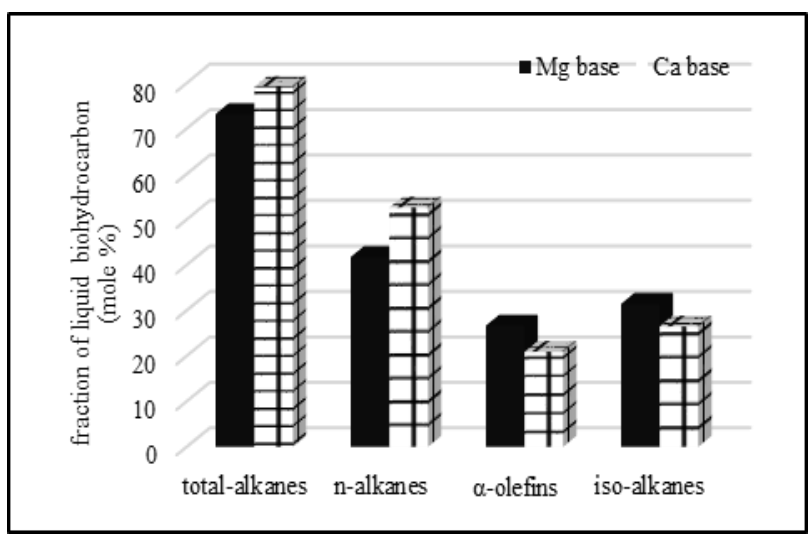

Fig. 3. percentages of $\mathrm{C}_{8}-\mathrm{C}_{20}$ total alkanes, n-alkanes, isoalkanes and $\alpha$-olefins formed.

Figure 3 shows that, about $78 \%$-mole of liquid biohydrocarbons produced from the decarboxylation of the calcium basic soaps are alkane compounds (i.e., nparaffin + iso-paraffin), as would be expected in green diesel. The rest (approxymately 20\%-mole) are various $\alpha$-olefin molecules. Whereas, only about $70 \%$-mole of alkanes resulted of magnesium basic soap. Therefore, the resulting $\alpha$-olefin of magnesium basic soap is high, i.e., about $27 \%$-mole or $7 \%$-mole more than the same product of calcium basic soap.

Figure 4 shows the molar ratio of the n-alkane fraction to 1-alkenes according to $\mathrm{C}_{8}-\mathrm{C}_{20}$ carbon number ranges of liquid biohydrocarbon of both magnesium and calcium basic soaps. Figure 4 shows that the molar ratio of $n$-alkanes to 1 -alkene is found to be higher for $\mathrm{C}_{14}$, $\mathrm{C}_{15}, \mathrm{C}_{18}$ and $\mathrm{C}_{19}$ in the liquid product of calcium basic soap. This shows that the decarboxylation of calcium basic soap produces the n-alkane more than 1-alkene fraction for $\mathrm{C}_{14}, \mathrm{C}_{15}, \mathrm{C}_{18}$ and $\mathrm{C}_{19}$ molecules. In other words, calcium has high selectivity toward the formation 
of long chain n-alkane products, as which are expected to green diesel fuel. The more balanced the amount of the n-alkanes and 1 -alkenes in the liquid product, its molar ratio close to one, as indicated by the $\mathrm{C}_{8}-\mathrm{C}_{11}$ molecules.

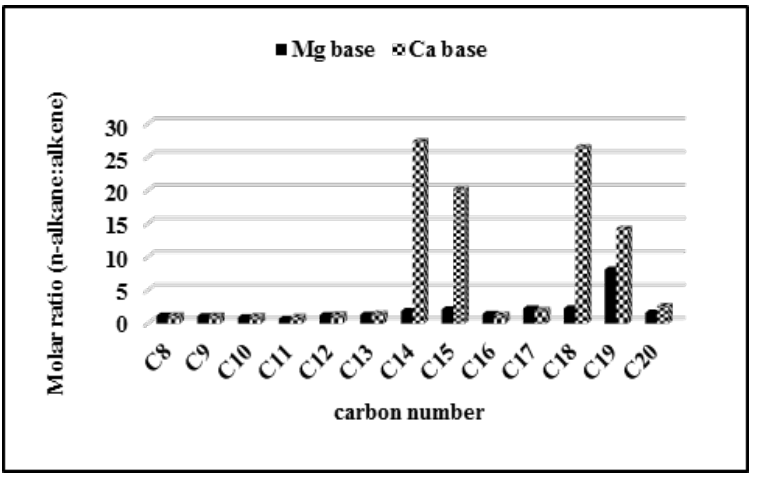

Fig. 4. The molar ratio of n-alkanes to 1-alkenes.

Decarboxylation of magnesium basic soap, yields a low n-alkane to 1 -alkenes ratio. The same result occurs almost in all components of the liquid biohydrocarbon fractions, i.e., from the $\mathrm{C}_{8}-\mathrm{C}_{20}$ molecule. Therefore, magnesium has low selectivity or is not specific to the formation of n-alkanes. Even magnesium tend to increase of 1-alkene product.

Figure 5 shows the profile of the molar yield of nalkanes in the range of $\mathrm{C}_{18}-\mathrm{C}_{20}$ carbon number, resulted from both magnesium and calcium basic soaps.

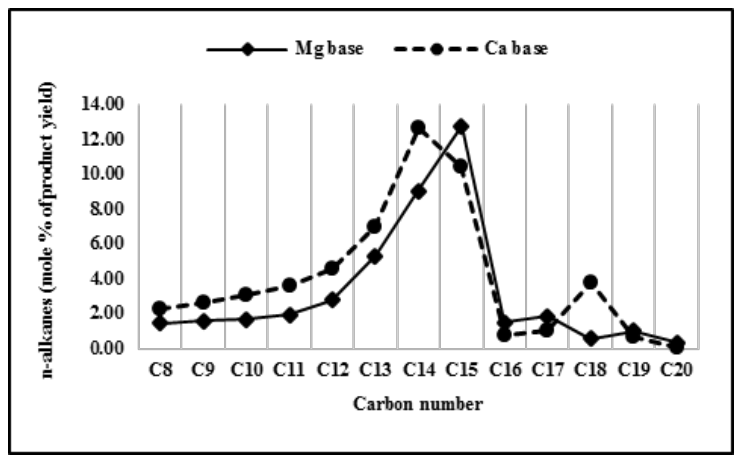

Fig. 5. Molar yield of $\mathrm{C}_{8}-\mathrm{C}_{20}$ n-alkanes at $370^{\circ} \mathrm{C}$ for 5 hours.

Figure 5 shows that about 10\%-mole and 13\%-mole of $53 \%$-mol total of n-alkane fraction (in the carbon number range $\mathrm{C}_{8}-\mathrm{C}_{20}$ ) resulting from decarboxylation of a calcium basic soap are n-pentadecane $\left(n-C_{15}\right)$ and $n-$ tetradecane $\left(\mathrm{n}-\mathrm{C}_{14}\right)$, respectively. Whereas, only about $13 \%$-mole and $9 \%$-mole of $42 \%$-mol total n-alkanes, generated from magnesium basic soap are n-pentadecane and n-tetradecane, respectively. From the total yield of n-alkane products were resulted from calcium basic soaps, about $29 \%$-mole is a long chain alkane $\left(\mathrm{C}_{14}-\mathrm{C}_{18}\right)$ suitable for green diesel, while only about $26 \%$-mole of magnesium base soap. The n-octadecane product is detected in significant amounts (about 4\%-mole), only in the liquid product of decarboxylation of the calcium basic soap. Apparently, the calcium may act as a polymerization catalyst of short chain to long chain biohydrocarbons.

\section{Conclusions}

Magnesium and calcium basic soaps, can be converted to liquid biohydrocarbon or drop-in fuels, especially green diesel via decarboxylation method. Green diesel generated from calcium basic soaps, contains 78\%-mole total alkanes, higher than magnesium basic soap (only about $70 \%$-mole). No ketone compound is detected in green diesel produced by calcium basic soap. The product distribution, in particular the concentration of the saturated $\mathrm{C}_{14}$ and $\mathrm{C}_{15}$ biohydrocarbons, is significantly higher in the green diesel produced by calcium basic soaps. This proves that, the use of calcium in basic soaps, significantly increases the selectivity to long chain n-alkane products (especially $\mathrm{C}_{14}, \mathrm{C}_{15}$ and $\mathrm{C}_{18}$ ), which are expected by green diesel fuel.

\section{References}

1. J. J. Yoon, Advanced Biofuels USA, 2006

2. I. Kubic kova', M. Sna ${ }^{\circ}$ re, K. Era“nen, P. M. Arvela, D. Y. Murzin, Catal. Today 106, 197-200 (2005)

3. C. Chang, S. Wan, Ind. and Eng. Chem 39, 15431548 (1947)

4. Klare S. Markley, Fatty Acids, (Intersciences Publisher INC, New York, 1947)

5. A. Zhang, Q. Ma, K. Wang, X. Liu, P. Shuler, Y. Tang, Appl. Catal. A: General 303, 103 - 109 (2006)

6. J. G. Na, B. E. Yi, J. N. Kim, K. B. Yi, S. Y. Park, J. H. Park, C. H. Ko, Catal. Today 156, 44 - 48 (2010)

7. S. A. Khromova, A. A. Smirnov, S. A. Selishcheva, R. G. Kukushkin, V. O. Dundich, L. I. Trusov, V. A. Yakovlev, Biocatal. 5, 260 - 268 (2013)

8. W. Vermeiren, G. N. Van, Paten WO2011012439A1, 1 - 15 (2011)

9. G. Yasin, M. I. Bhanger, T. M. Ansari, S. M. S. R. Navqi, F. N. Talpur, J of Petro. Techn. and Alternatif Fuels 3, 29-35 (2012)

10. G. Knothe, A. C. Matheus, T. W. Ryan, Fuel 82, 971-975 (2003)

11. Ynowitz J., Ratclift M. A., McCormick R. L., Taylor J. D., Murphy M. J., National Renewable Energy Laboratory (2014)

12. M. Sato, J. Soc. Chem. Ind. Japan 30, 252-260 (1927)

13. H. L. Hsu, J. O. Osburn, C. S. Grove Jr, Ind. and Eng. Chem. 42, $2141-2145$ (1950) 